\title{
Dynamic Model and Controller Design for Active Power Filter in Three-Phase Four-Wire System
}

\author{
Phonsit Santiprapan, Kongpol Areerak and Kongpan Areerak \\ School of Electrical Engineering \\ Suranaree University of Technology, SUT \\ Nakhon Ratchasima, THAILAND \\ b4904144@hotmail.com,kongpol@sut.ac.th,kongpan@sut.ac.th
}

\begin{abstract}
This paper presents the dynamic model and control strategy of active power filter (APF) on dq0-frame in three-phase four-wire system. The structure of the APF is the three-leg splitcapacitor. The dq0-frame with Fourier (DQF) method is used to calculate the reference currents on dq0-frame. The pulse width modulation (PWM) with PI controllers is considered in the paper. Moreover, the principle of the PI controller design for three current loops and two voltage loops are completely presented. The discrete design approach is used to design all controllers in the system. In addition, the hardware in the loop (HIL) technique is applied to simulate the harmonic elimination using the APF in the paper. The results show that the control strategy and the design approach presented in the paper can provide the good performance of the APF. Furthermore, the source currents after compensation can also follow the IEEE Std.519-1992 and IEEE Std.1459-2010.
\end{abstract}

Keywords: dq0-frame with Fourier algorithm, active power filter, dynamic model, dq0 control strategy, hardware in the loop (HIL)

\section{Introduction}

Nonlinear loads are the major harmonic source for power system networks. Harmonics cause a lot of problems such as loss in transmission lines and electric devices, protective device failures and short-life electronic equipments in the system [1] - [4]. Therefore, it is necessary to reduce or eliminate the harmonics in the system. Presently, it is well known that the harmonic elimination using an active power filter (APF) [5] provides higher efficiency and more flexible compared with a passive power filter [6]. Thus, the APF is considered to eliminate the harmonic currents in the paper. There are four main parts to be considered for using the APF as shown in Figure 1.

The first part is the structure of APF. In three-phase four-wire system, nonlinear loads are often unbalanced condition. There are many structures to solve these problems [7] such as the three H-bridge topology, the three-leg split-capacitor topology and four-leg topology. In this paper, the three-leg split-capacitor topology with six IGBTs is used because this topology provides a good performance for a harmonic elimination [8] and it uses the lower number of power semiconductor devices [9].

The harmonic detection algorithm for calculating the reference currents of the APF is the second part. From the literature survey, there are many algorithms such as the instantaneous power theory (PQ) [10], the synchronous reference frame (SRF) [11], the synchronous detection (SD) [12], the ABC reference frame [13], the DQ axis with Fourier (DQF) [14] [15] and the perfect harmonic cancellation [16]. In this paper, the $d q 0$-frame with Fourier (DQF) algorithm is selected for the harmonic detection part because this algorithm is flexible 
to operate with three-phase balanced and unbalanced systems. Furthermore, the DQF method also provides the fast calculation time in which it is suitable for the real time applications.

The third part is the controller design and control strategy to control the injection of compensating currents. There are several techniques to control the compensating currents of APF [17]. The pulse width modulation (PWM) with PI controllers on $d q 0$-frame is used for current loop controls. The detail of the PI controllers design for three current loops based on the dynamic model is also proposed. In the paper, the delay time is considered in the control system. Therefore, the discrete design approach [18] is used to design the PI controllers. In addition, the phase locked-loop (PLL) circuit [19] is adopted to operate with the current control scheme of APF for the phase angle calculation.

The fourth part is the DC bus voltage control of APF. The one problem of the three-leg split-capacitor topology is the voltage deviation between the dc capacitors $\left(C_{d c, 1}, C_{d c, 2}\right)$ [9]. For this reason, the design of voltage loop controllers and control strategy are used to keep the balanced voltage across the capacitors $\left(V_{d c, 1}, V_{d c, 2}\right)$. The $V_{d c, 1}$ and $V_{d c, 2}$ are controlled by the proposed voltage control system to regulate the voltages equal to the desired operating point. There are various types of the voltage controllers such as PI controller [20], fuzzy logic controller [21] and sliding mode controller [22]. In the paper, the PI controllers designed by discrete design approach is used to control the DC bus voltages because these controllers can provide the good transient and steady state responses.

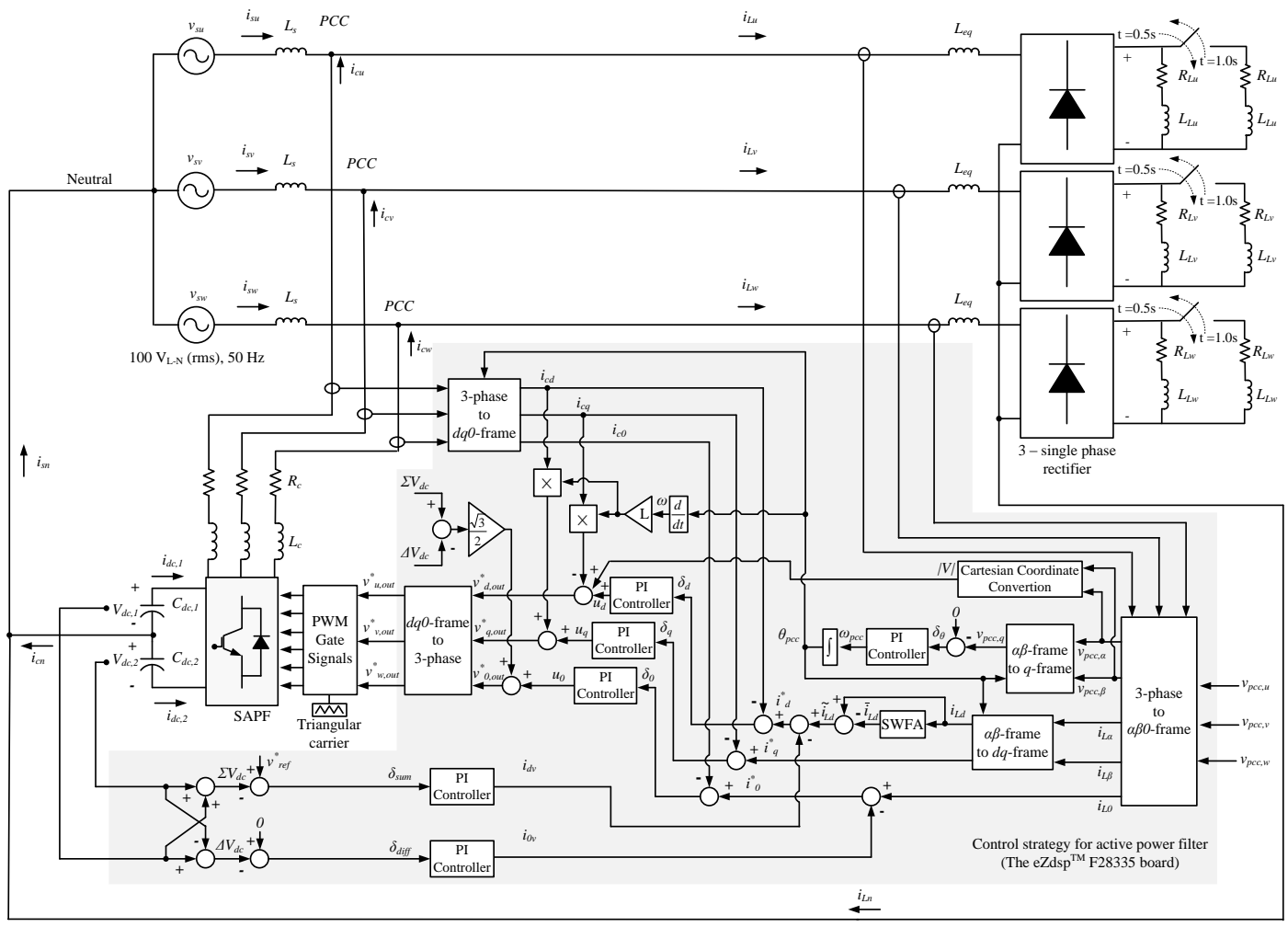

Figure 1. Considered Power System and Control Strategy

The Part 2, Part 3, and Part 4 are the significant part to achieve the good performance of APF. The DQF method in Part 2 is continuously developed by authors in the previous works. Therefore, the focus of the paper is to design the control strategy and the parameters of PI controllers using the discrete design approach called the "conventional approach". The aim of 
this paper is the small $\% T H D_{i, a v}$ and $\% C U F$ of source currents and unity power factor after compensation by using APF.

The paper is structured as follows. The review of the $d q 0$-frame with Fourier algorithm is summarily described in Section 2.The review of mathematical model for three-phase fourwire active power filter is briefly explained in Section 3. In Section 4, the conventional design of the PI controllers using the discrete design approach are fully presented. Moreover, Section 5 presents the hardware in the loop simulation to simulate the harmonic elimination of the system using the APF. The simulation results and discussions of the harmonic elimination are completely shown in Section 6. Finally, Section 7 concludes the purposes of this paper.

\section{Review of $\boldsymbol{d q 0}$-frame with Fourier (DQF) Algorithm}

The DQF algorithm is the excellent method to identify the harmonic in the power system. This method is a combination between the advantages of the synchronous reference frame method (SRF) [11] and the sliding window Fourier analysis (SWFA) [23]. The DQF method is firstly presented in 2007 by Sarawut Sujitjorn, Kongpol Areerak and Thanatchai Kulworawanichpong [14]. In 2007, the DQF method is operated with only the APF to eliminate all harmonic components in the system. In 2008, Kongpol Areerak extends the work in [14] to apply the DQF method operated with the hybrid power filter to eliminate some harmonic components depending on the engineering design. In this section, the detail of the DQF method to identify the harmonic current on the $d q 0$-frame in the system is presented. The flowchart of overall procedure to calculate the harmonic currents on $d q 0$-frame $\left(\tilde{i}_{L d}, i_{q}^{*}\right.$, $\left.i_{L 0}\right)$ using the DQF method is illustrated in Figure 2. The more details of the DQF method can be found in [14] and [15].

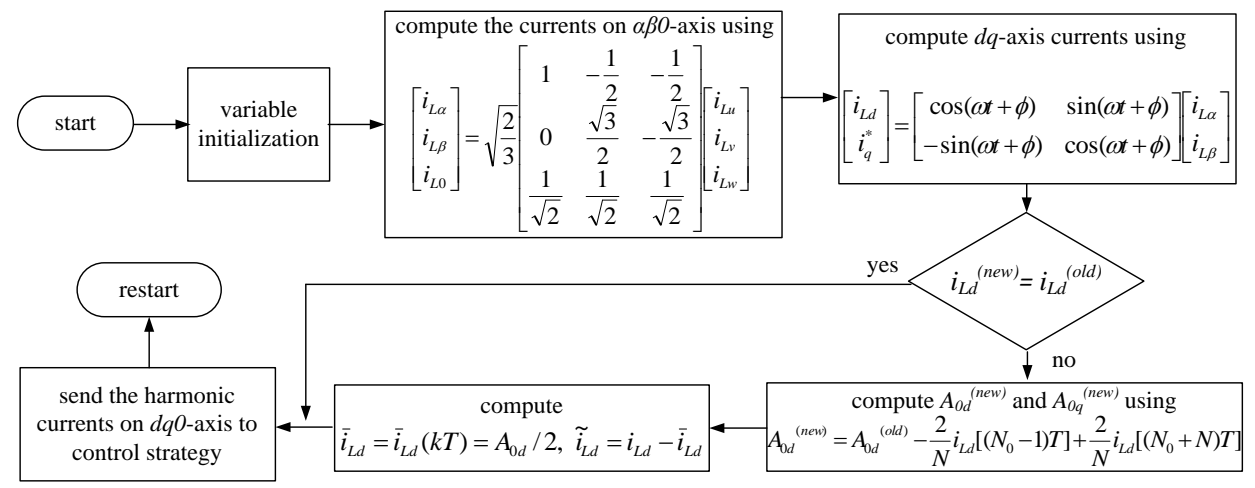

Figure 2. Flowchart of the DQF Method

\section{Review of Mathematical Model for Three-Phase Four-Wire Active Power Filter}

The three-leg split-capacitor APF in Figure 3 is the considered system used to derive the mathematical model. The considered APF is modeled in the stationary $u v w$-frame and the rotating $d q 0$-frame.The review of mathematical model for three-phase four-wire APF can be outlined as follows: 


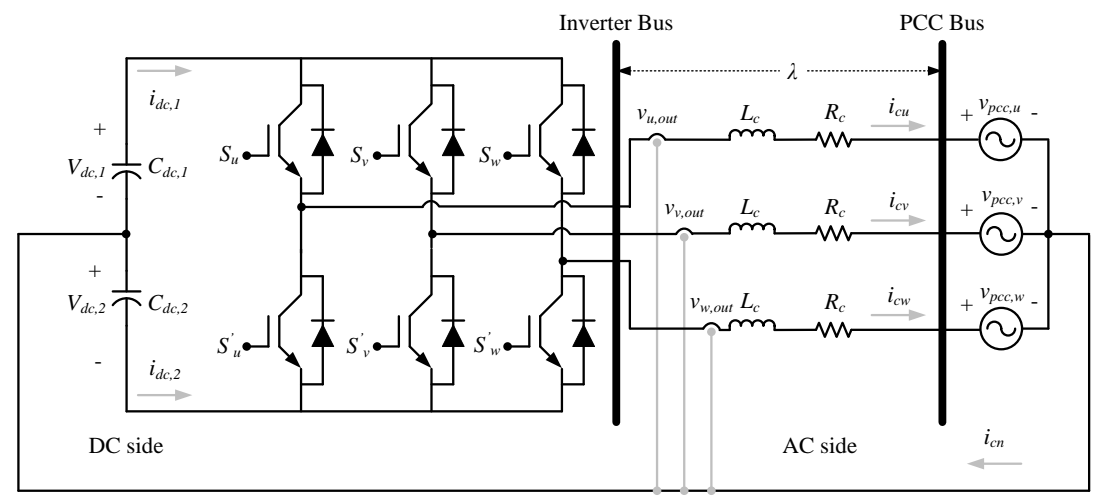

Figure 3. The Equivalent Circuit of APF in Three-phase Four-wire System

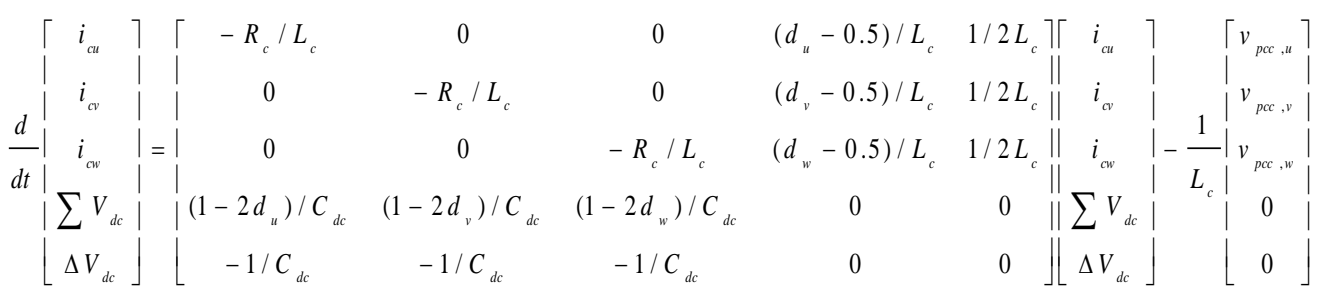

From the AC and the DC sides, the Kirchhoff's law is used to determine the three-phase compensating currents $\left(i_{c u}, i_{c v}, i_{c w}\right)$, the total DC bus voltage across the capacitors $\left(\Sigma V_{d c}=\right.$ $\left.V_{d c, 1}+V_{d c, 2}\right)$ and the different DC bus voltage between two capacitors $\left(\Delta V_{d c}=V_{d c, 1}-V_{d c, 2}\right)$. The dynamic model of the APF on stationary $u v w$-frame in term of the state variable model can be written by (1).

In the paper, the $d q 0$ approach is used to describe the control strategy of the system. Therefore, the mathematical model on three-phase four-wire system in (1) can be transformed into the $d q 0$-frame using the transformation matrix (Park's transformation).

The $\omega$ is the angular frequency of the PCC voltage vector $\left(v_{p c c}\right)$ as shown in the vector diagram in Figure 4. In the paper, the phase shift $(\lambda)$ between the PCC bus and the inverter bus is neglected. The $d$-axis is aligned along the vector $\left(\phi=\phi_{1}\right)$. From this assumption, the dynamic model of the APF on $d q 0$-frame in term of the state variable model can be written by (2).

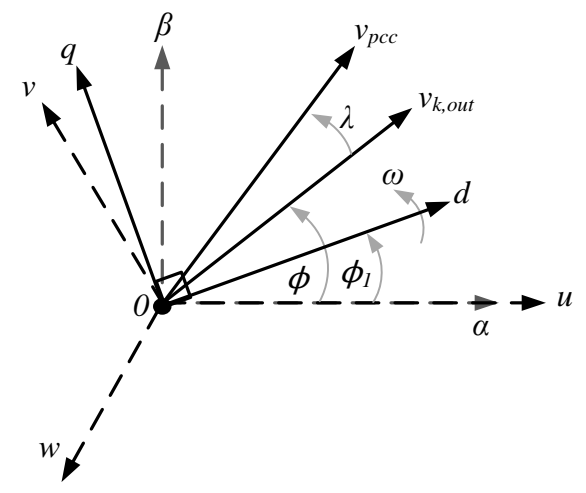

Figure 4. The Vector Diagram of the dq0-frame 


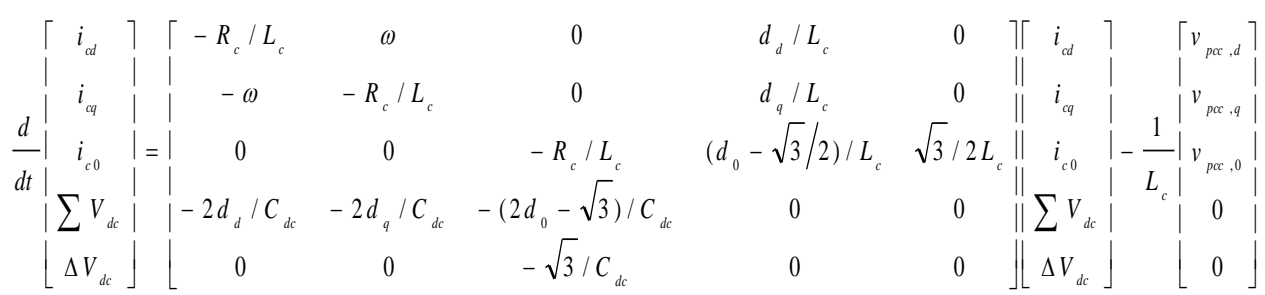

\section{Controls of Active Power Filter}

In the paper, the PI controllers are applied to control the compensating currents and the DC bus voltage of the APF for harmonic elimination in the system. The dynamic model derived in Section 3 is referred to describe the control strategy of the system. The designs of current and voltage loop controllers based on the discrete design method are proposed in this section.

\subsection{Design of Current Loop Control}

The differential equations of the compensating currents on $d q 0$-frame can be arranged by substituting (3) to (2). The output voltages of the APF on $d q 0$-frame $\left(v_{d, \text { out }}, v_{q, \text { out }}, v_{0, \text { out }}\right)$ are shown by (3). On the $d q 0$-frame, the $v_{p c c, d}$ is equal to $|V|$, while $v_{p c c, q}$ and $v_{p c c, o}$ are equal to zero.

$$
\begin{aligned}
& {\left[\begin{array}{lll}
v_{d, \text { out }} & v_{q, \text { out }} & v_{0, \text { out }}
\end{array}\right]^{T}=\sum V_{d c} \cdot\left[\begin{array}{lll}
d_{d} & d_{q} & d_{0}
\end{array}\right]^{T}} \\
& |V|=\omega L_{c} i_{c q}+d_{d} \sum V_{d c}-L_{c} \frac{d i_{c d}}{d t}-R_{c} i_{c d} \\
& 0=-\omega L_{c} i_{c d}+d_{q} \sum V_{d c}-L_{c} \frac{d i_{c q}}{d t}-R_{c} i_{c q} \\
& 0=-\frac{\sqrt{3}}{2}\left(\sum V_{d c}-\Delta V_{d c}\right)+d_{0} \sum V_{d c}-L_{c} \frac{d i_{c 0}}{d t}-R_{c} i_{c 0}
\end{aligned}
$$

From (4) - (6), the reference voltages of the APF on $d q 0$-frame $\left(v_{d, \text { out }}^{*}, v_{q, \text { out }}^{*}, v_{0, \text { out }}^{*}\right)$ are illustrated in (7) - (9).

$$
\begin{aligned}
& v_{d, \text { out }}^{*}=u_{d}-\omega L_{c} i_{c q}+|V| \\
& v_{q, \text { out }}^{*}=u_{q}+\omega L_{c} i_{c d} \\
& v_{0, \text { out }}^{*}=u_{0}+\frac{\sqrt{3}}{2}\left(\sum V_{d c}-\Delta V_{d c}\right)
\end{aligned}
$$

The output signals of plant on $d q 0$-frame $\left(u_{d}, u_{q}, u_{0}\right)$ can be seen in (10).

$$
\left[\begin{array}{lll}
u_{d} & u_{q} & u_{0}
\end{array}\right]^{T}=L_{c} \cdot\left[\begin{array}{lll}
\frac{d i_{c d}}{d t} & \frac{d i_{c q}}{d t} & \frac{d i_{c 0}}{d t}
\end{array}\right]^{T}+R_{c} \cdot\left[\begin{array}{lll}
i_{c d} & i_{c q} & i_{c 0}
\end{array}\right]^{T}
$$

From (7) - (9), the control strategy of the compensating currents of the APF is depicted in Figure 1. The plants to design the PI controllers for three current loops can be derived from (10) by using the Laplace transform as shown in (11).

$$
G_{p c}(s)=\frac{I_{c d}(s)}{U_{d}(s)}=\frac{I_{c q}(s)}{U_{q}(s)}=\frac{I_{c 0}(s)}{U_{0}(s)}=\frac{1}{L_{c} s+R_{c}}
$$


It can be seen from Figure 1 that the output signals of the PI controllers on $d q 0$-frame $\left(u_{d}, u_{q}, u_{0}\right)$ are obtained by (12).

$$
\left[\begin{array}{lll}
u_{d} & u_{q} & u_{0}
\end{array}\right]^{T}=K_{p c} \cdot\left[\begin{array}{lll}
\delta_{d} & \delta_{q} & \delta_{0}
\end{array}\right]^{T}+K_{i c} \cdot\left[\begin{array}{lll}
\delta_{d} d t & \int \delta_{q} d t & \int \delta_{0} d t
\end{array}\right]^{T}
$$

From (12), the transfer functions of the PI controllers on $d q 0$-frame $\left(G_{c}(s)\right)$ are shown in (13).

$$
G_{c}(s)=\frac{U_{d}(s)}{\delta_{d}(s)}=\frac{U_{q}(s)}{\delta_{q}(s)}=\frac{U_{0}(s)}{\delta_{0}(s)}=\frac{\left(K_{p c} s+K_{i c}\right)}{s}
$$

The discrete design approach is used to design the PI controllers in the paper. The design procedure to obtain the appropriate parameters of the PI controllers can be summarized as follows:

Step 1: Define the bandwidth of the current loops control $\left(\omega_{n i}\right)$. The maximum harmonic order considered in the system is equal to 50 and the fundamental frequency is $50 \mathrm{~Hz}$. Thus, the $\omega_{n i}$ is set to $2 \pi \times 2500 \mathrm{rad} / \mathrm{s}$ in the paper. In addition, the damping ratio $(\zeta)$ is defined to 0.707 and the sampling time $\left(T_{s}\right)$ is set to $10 \mu \mathrm{s}$.

Step 2: Find the discrete transfer function of the plant $\left(G_{p c}(z)\right)$ using a zero-order hold $(\mathrm{ZOH})$ as shown in (14).

$$
\left.G_{p c}(z)=\left(1-z^{-1}\right) \cdot Z\left\{\frac{G_{p c}(s)}{s}\right\}=\frac{1}{R_{c}} \mid \frac{1-e^{-\frac{R_{c} T_{s}}{L_{c}}}}{z-e^{-\frac{R_{c} T_{s}}{L_{c}}}}\right\}
$$

Step 3: The transfer function of the PI controller in (13) can be transformed into zdomain as shown in (15). The $\alpha$ is the location of the zero in the z-plane.

$$
G_{c}(z)=\left.\frac{\left(K_{p c} s+K_{i c}\right)}{s}\right|_{s=\frac{z-1}{T_{s}}}=K_{p c}+\frac{K_{i c} T_{s}}{z-1}=K_{p c}\left(\frac{z-\alpha}{z-1}\right)=K_{p c}\left(\frac{z-\left(1-K_{i c} T_{s} / K_{p c}\right)}{z-1}\right)
$$

From (14) and (15), the block diagram including the computational delay is depicted in Figure 5. It is used to design the PI controller on $d q 0$-frame.

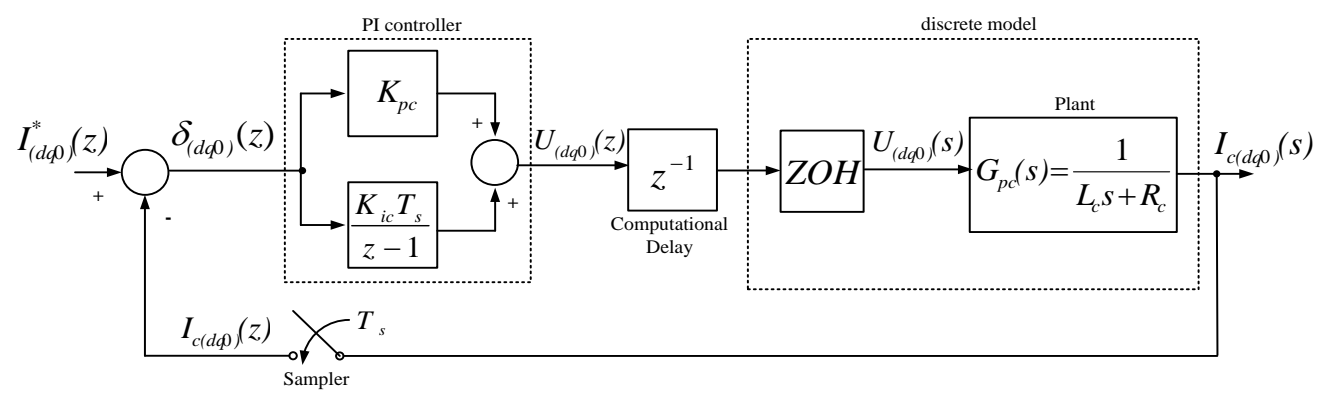

\section{Figure 5. The Block Diagram to Design the PI Controllers on dq0-frame for Three Current Loops}

From the block diagram in Figure 5, the closed-loop transfer function on $d q 0$-frame can be seen in (16). This equation is used to analyze the characteristic behavior of the system. 


$$
\frac{I_{(d q 0)}(z)}{I_{(d q)}^{*}(z)}=\frac{\left(K_{p c} / R_{c}\right)\left(1-e^{-R_{c} T_{s} / L_{c}}\right)(z-\alpha)}{z^{3}-\left(e^{-R_{c} T_{s} / L_{c}}+1\right) z^{2}+\left(e^{-R_{c} T_{s} / L_{c}}+\left(K_{p c} / R_{c}\right)\left(1-e^{-R_{c} T_{s} / L_{c}}\right)\right) z-\left(K_{p c} / R_{c}\right)\left(1-e^{-R_{c} T_{s} / L_{c}}\right) \alpha}
$$

Step 4: Determine the desired dominant poles in z-plane by (17).

$$
z=e^{T_{s}\left(-\xi \omega_{n} \pm j \omega_{n} \sqrt{1-\xi^{2}}\right)}=0.8902 \pm j 0.1003
$$

Step 5: Calculate the values of $\alpha$ and $K_{p c}$ by using the root-locus technique in z-plane. Substituting these values in (15) gives (18). The root-locus of the current control is shown in Figure 6.

$$
G_{c}(z)=569.33\left(\frac{z-0.9108}{z-1}\right)
$$

From (18), the appropriate PI controller parameters using in the paper are $K_{p c}=569.33$ and $K_{i c}=5.17 \times 10^{6}$.

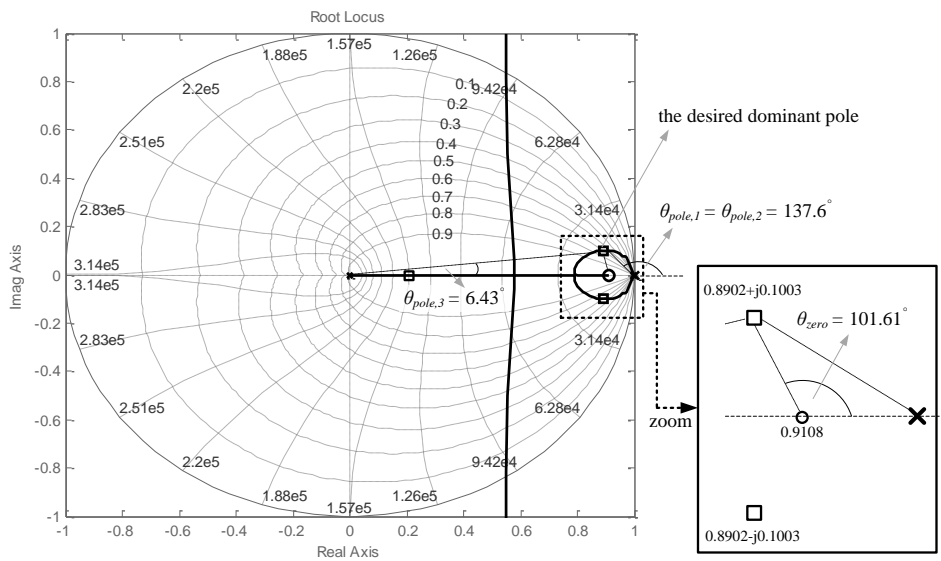

\section{Figure 6. The Root - locus of the Current Control}

\subsection{Design of Voltage Loop Control}

The differential equations of the $\Sigma V_{d c}$ and $\Delta V_{d c}$ in (2) can be rewritten as shown in (19) and (20), respectively. The $i_{d c \text {,sum }}$ and $i_{d c, \text { diff }}$ are the dc-link currents.

$$
\begin{aligned}
& C_{d c} \frac{d}{d t} \sum V_{d c}=i_{d c, s u m}=-2 d_{d} i_{c d}-2 d_{q} i_{c q}-2 d_{0} i_{c 0}+\sqrt{3} i_{c 0} \\
& C_{d c} \frac{d}{d t} \Delta V_{d c}=i_{d c, d i f f}=-\sqrt{3} i_{c 0}
\end{aligned}
$$

The plant for the PI controller design of the voltage loop can be derived from (19) and (20) by using the Laplace transform as shown in (21).

$$
G_{p v}(s)=\frac{\sum V_{d c}(s)}{I_{d c, s u m}(s)}=\frac{\Delta V_{d c}(s)}{I_{d c, d i f f}(s)}=\frac{1}{C_{d c} s}
$$

From Figure 1, the output of the PI controllers can be described by (22) and (23). Therefore, the transfer functions of the PI controllers for voltage loops are shown in (24) and (25). 


$$
\begin{aligned}
& i_{d v}=K_{p v, \text { sum }} \delta_{\text {sum }}+K_{i v, \text { sum }} \int \delta_{\text {sum }} d t \\
& i_{0 v}=K_{p v, \text { diff }} \delta_{d i f f}+K_{i v, d i f f} \int \delta_{d i f f} d t \\
& G_{c, \text { sum }}(s)=\frac{I_{d v}(s)}{\delta_{\text {sum }}(s)}=\frac{\left(K_{p v, \text { sum }} s+K_{i v, \text { sum }}\right)}{s} \\
& G_{c, \text { diff }}(s)=\frac{I_{0 v}(s)}{\delta_{d i f f}(s)}=\frac{\left(K_{p v, \text { diff }} s+K_{i v, d i f f}\right)}{s}
\end{aligned}
$$

From Figure 3, the AC side power is equal to the DC side power as shown in (26). The losses in capacitor, resistor and inductor are neglected as the condition of this equation.

$$
V_{d c} i_{d c, s u m}=-2\left(d_{d} V_{d c} i_{c d}+d_{q} V_{d c} i_{c q}+d_{0} V_{d c} i_{c 0}\right)+\sqrt{3} V_{d c} i_{c 0}
$$

In the paper, the PWM technique is applied to generate the switching signals. The power conserving convention of the $d q 0$ transformation is also used. Hence, (26) can be rewritten by (27). The $M$ in the equations is the modulation index of the desired operating point.

$i_{d c, s u m}=-\sqrt{3 / 2} \cdot M \cdot i_{d v}$

Taking z-transform in (20) and (27) gives (28) and (29), respectively.

$$
\begin{aligned}
& \frac{I_{d c, d i f f}(z)}{I_{0 v}(z)}=-\sqrt{3} \\
& \frac{I_{d c, s u m}(z)}{I_{d v}(z)}=-\sqrt{3 / 2} \cdot M
\end{aligned}
$$

In this section, the procedure to design the PI controllers for voltage loops is the same as the design of the current loops. The overall procedure for the controllers design can be outlined as follows:

Step 1: The bandwidth of the voltage loops $\left(\omega_{n v}\right)$ are set to $2 \pi \times 10 \mathrm{rad} / \mathrm{s}$ in this paper. The damping ratio $(\zeta)$ is still set to 0.707 .

Step 2: The plant $\left(G_{p v}(z)\right)$ using the $\mathrm{ZOH}$ can be seen in (30).

$$
G_{p v}(z)=\left(1-z^{-1}\right) \cdot Z\left\{\frac{G_{p v}(s)}{s}\right\}=\frac{T_{s}}{C_{d c}}\left(\frac{1}{z-1}\right)
$$

Step 3: The transfer functions of the PI controllers in (24) and (25) can be transformed into Z-domain as shown in (31) and (32), respectively. The $\alpha_{\text {sum }}$ and $\alpha_{\text {diff }}$ are the zero locations.

$$
\begin{gathered}
G_{c, \text { sum }}(z)=\left.\frac{\left(K_{p v, s u m} s+K_{i v, \text { sum }}\right)}{s}\right|_{s=\frac{z-1}{T_{s}}}=K_{p v, \text { sum }}+\frac{K_{i v, \text { sum }} T_{s}}{z-1}=K_{p v, \text { sum }}\left(\frac{z-\alpha_{s u m}}{z-1}\right)=K_{p v, s \text { sum }}\left(\frac{z-\left(1-\left(K_{i v, s u m} T_{s} / K_{p v, \text { sum }}\right)\right)}{z-1}\right) \\
G_{c, \text { diff }}(z)=\left.\frac{\left(K_{p v, \text { diff }} s+K_{i v, \text { diff }}\right)}{s}\right|_{s=\frac{z-1}{T_{s}}}=K_{p v, \text { diff }}+\frac{K_{i v, \text { diff }} T_{s}}{z-1}=K_{p v, \text { diff }}\left(\frac{z-\alpha_{\text {diff }}}{z-1}\right)=K_{p v, \text { diff }}\left(\frac{z-\left(1-\left(K_{i v, \text { diff }} T_{s} / K_{p v, \text { diff }}\right)\right)}{z-1}\right)
\end{gathered}
$$

From (24), (29) and (31), the block diagram of the total DC bus voltage loop including the computational delay is illustrated in Figure 7(a). From (25), (28) and (32), the block diagram of the different DC bus voltage loop including the computational delay is depicted in Figure $7(b)$. 
From the block diagrams in Figure 7(a)-(b), the closed-loop transfer functions are shown in (33) and (34), respectively.

$$
\begin{aligned}
& \frac{\sum V_{d c}(z)}{V_{r e f}^{*}(z)}=\frac{\sqrt{\frac{3}{2}} M \frac{K_{p v, s u m} T_{s}}{C_{d c}}\left(z-\alpha_{s u m}\right)}{z^{3}-2 z^{2}+\left(\sqrt{\frac{3}{2}} M \frac{K_{p v, s u m} T_{s}}{C_{d c}}+1\right) z-\sqrt{\frac{3}{2}} M \frac{K_{p v, s u m} T_{s}}{C_{d c}} \alpha_{s u m}} \\
& \frac{\Delta V_{d c}(z)}{R(z)}=\frac{\sqrt{3} \frac{K_{p v, \text { diff }} T_{s}}{C_{d c}}\left(z-\alpha_{d i f f}\right)}{z^{3}-2 z^{2}+\left(\sqrt{3} \frac{K_{p v, d i f f} T_{s}}{C_{d c}}+1\right) z-\sqrt{3} \frac{K_{p v, d i f f} T_{s}}{C_{d c}} \alpha_{d i f f}}
\end{aligned}
$$

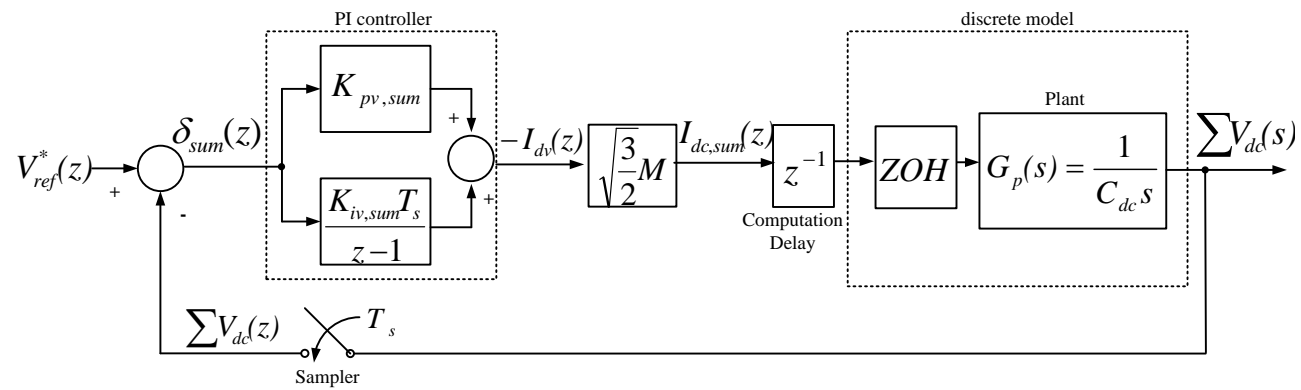

(a) The Total DC bus voltage loop

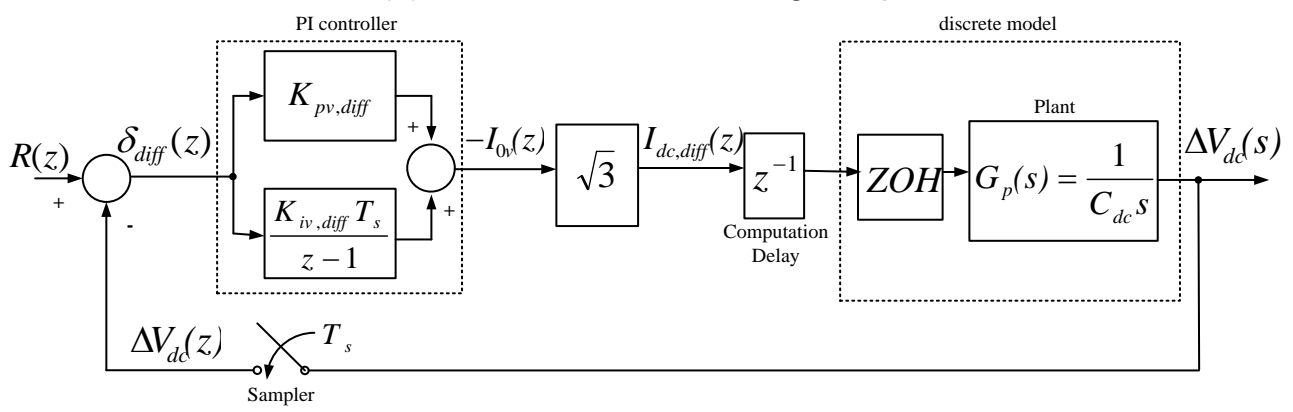

(b) The different DC bus voltage loop

Figure 7. The Block Diagram to Design the PI Controllers

Step 4: Determine the desired dominant poles in z-plane by (35).

$$
z=e^{T_{s}\left(-\xi \omega_{n} \pm j \omega_{n} \sqrt{1-\xi^{2}}\right)}=0.9996 \pm j 0.0004
$$

Step 5: Find the values of $\alpha_{\text {sum }}, \alpha_{\text {diff }}, K_{p v, \text { sum }}$ and $K_{p v \text {,diff }}$ by using the root-locus technique in Figure 8. Substituting these values in (31) and (32) gives (36) and (37), respectively. The PI controllers for voltage loops are $K_{p v, \text { sum }}=0.2714, K_{i v, \text { sum }}=10.8540$, $K_{p v, \text { diff }}=0.1363$ and $K_{i v, \text { diff }}=5.4519$.

$$
\begin{aligned}
& G_{c, \text { sum }}(z)=0.2714\left(\frac{z-0.9996}{z-1}\right) \\
& G_{c, \text { diff }}(z)=0.1363\left(\frac{z-0.9996}{z-1}\right)
\end{aligned}
$$



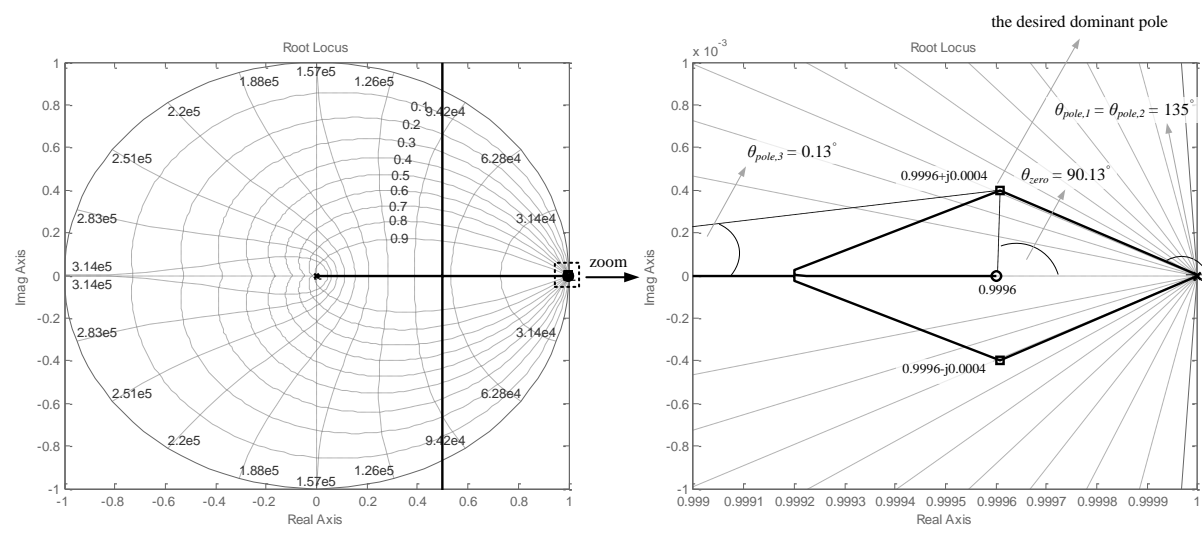

Figure 8. The Root-locus of the Voltage Control

\section{Hardware in the Loop Simulation}

In the paper, the hardware in the loop (HIL) simulation technique is applied to simulate the harmonic elimination using APF with the controllers proposed in the previous section. The diagram of the HIL simulation is shown in Figure 9. It can be seen that the SPSTM SIMULINK in the host computer is cooperated with the Code Composer Studio ${ }^{\mathrm{TM}}$ in the eZdspTM F28335 board.

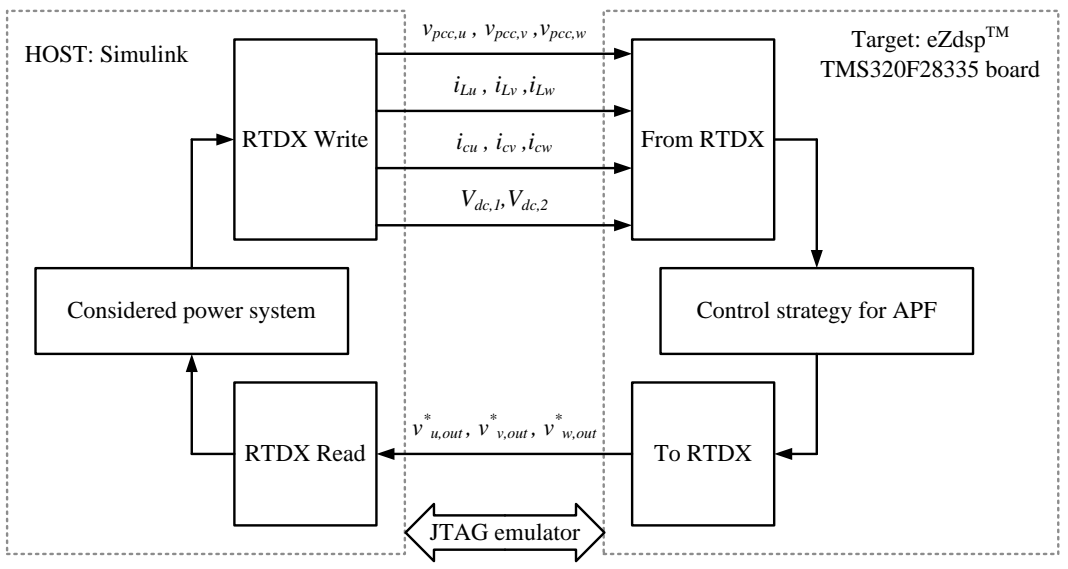

Figure 9. Hardware in the Loop Simulation

The hardware connection between the host computer and the eZdsp ${ }^{\mathrm{TM}} \mathrm{F} 28335$ board by the JTAG emulator can be seen in Figure 10. From Figure 9, the three-phase voltages at a PCC point $\left(v_{p c c, u}, v_{p c c, v}, v_{p c c, w}\right)$, the load currents $\left(i_{L u}, i_{L v}, i_{L w}\right)$, the compensating currents $\left(i_{c u}, i_{c v}, i_{c w}\right)$ and the DC bus voltages $\left(V_{d c, 1}, V_{d c, 2}\right)$ are measured from the considered power system in the SPS ${ }^{\mathrm{TM}}$ SIMULINK. The "RTDX Write" is used to send these data from the host computer to the eZdsp ${ }^{\mathrm{TM}} \mathrm{F} 28335$ board. While, the "From RTDX" is adopted to receive these data from the host into target. In the eZdsp ${ }^{\mathrm{TM}} \mathrm{F} 28335$ board, the informations from the host are calculated by control strategy process to obtain the reference output three-phase voltages of the inverter $\left(v_{u, \text { out }}^{*}, v_{v, \text { out }}^{*}, v_{w, \text { out }}^{*}\right)$. The $v_{u, \text { out }}^{*}, v_{v, \text { out }}^{*}$, and $v_{w, \text { out }}^{*}$ are transferred into the host computer by the "To RTDX". The "RTDX Read" is used to receive the data from target. For the next cycle, the HIL simulation can similarly be described in Figure 9. 


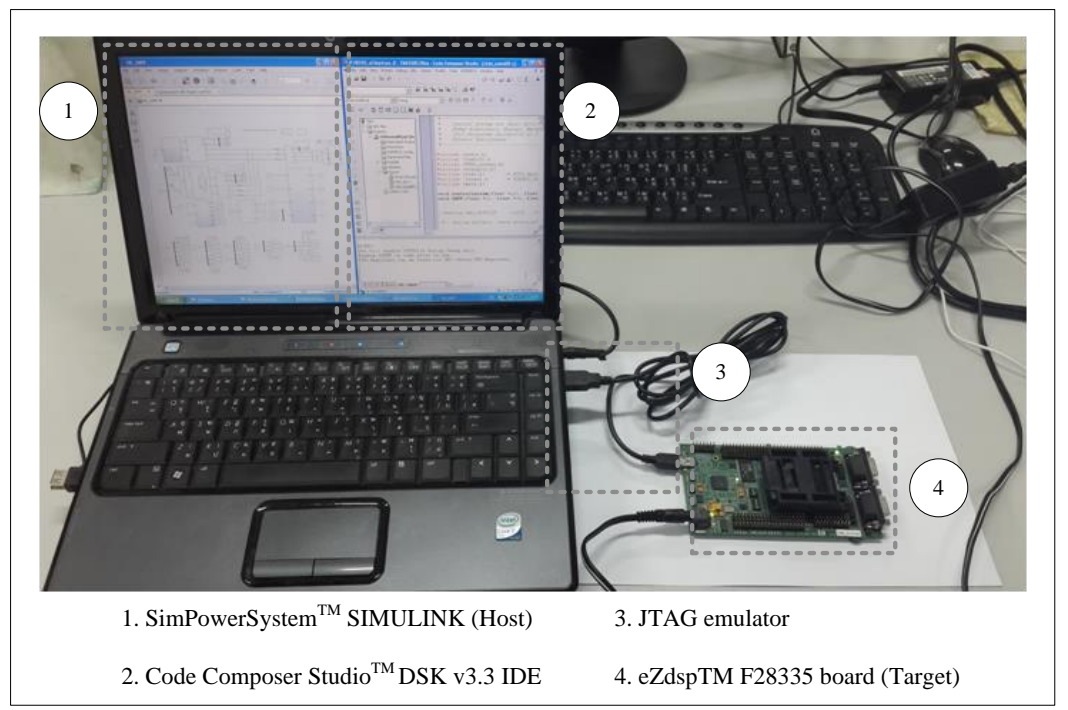

Figure 10. Hardware Connection of HIL Simulation

\section{Simulation Results and Discussion}

The harmonic mitigation system using APF with the control strategy proposed in the paper in Figure 1 is simulated by HIL explained in the previous section. In the paper, the three single-phase bridge rectifiers with different RL loads are the nonlinear load for an unbalanced three-phase four-wire system. It is well known that the nonlinear load can generate the harmonics into the system. Thus, the three-leg split-capacitor APF with six IGBTs is used to inject the compensating currents into the power system at a PCC point for harmonic mitigation. The APF can control the compensating currents to track the reference currents using the proposed control strategy. The simulation results of the system in Figure 1 with the system parameters from Table 1 are depicted in Figure 10-12.

Table 1. System Parameters

\begin{tabular}{|l|l|}
\hline Line voltage and frequency & $v_{p c, k}=100 \mathrm{~V}_{\mathrm{rms}}, f_{s}=50 \mathrm{~Hz}$ \\
\hline Line impedance & $L_{s}=0.1 \mathrm{mH}, L_{e q}=10 \mathrm{mH}$ \\
\hline \multirow{2}{*}{ 3-single phase diode rectifiers } & $L_{L u}=100 \mathrm{mH}, L_{L v}=150 \mathrm{mH}, L_{L w}=200 \mathrm{mH}$ \\
& $R_{L u}=30 \Omega, R_{L v}=40 \Omega, R_{L w}=50 \Omega$ \\
\hline \multirow{2}{*}{ DC bus voltages and Capacitors } & $V_{d c, l}=250 \mathrm{~V}, V_{d c, 2}=250 \mathrm{~V}$ \\
& $C_{d c, 1}=1000 \mu \mathrm{F}, C_{d c, 2}=1000 \mu \mathrm{F}$ \\
\hline Line impedance & $L_{c}=30 \mathrm{mH}$ \\
\hline Switching frequency & $f_{s w}=5000 \mathrm{~Hz}$ \\
\hline
\end{tabular}

For a three-phase four-wire system, The average total harmonic current distortion $\left(\% T H D_{i, a v}\right)$, the current unbalanced factor $(\% C U F)$ and the total power factor $(P F)$ are used as the performance indices of APF based on the IEEE Std.519-1992 [4] and the IEEE Std.1459-2010 [24]. The \%THD $D_{i, a v}, \% C U F$ and $P F$ can be calculated by (38)-(40), respectively. In the equations, $k$ means the phase $\mathrm{u}, \mathrm{v}$ or $\mathrm{w}, h$ is the harmonic order, the $\varphi_{k h}$ is the phase shift between the $h^{\text {th }}$ harmonic current and voltage for phase $k$. The subscripts ' + ' and ' 0 ' in these equations are the positive and zero sequences components, respectively. 


$$
\begin{aligned}
& \%_{i, a v}=\sqrt{\frac{\sum_{k=u, v, w} \% T H D_{i, k}^{2}}{3}} \\
& \% C U F=\frac{I_{s e}^{0}}{I_{s e}^{+}} \times 100 \% \\
& P F=\frac{P}{V_{p c c e} I_{s e}}=\frac{\sum_{k} \sum_{h} V_{p c c, k h} I_{s k, h} \cos \left(\varphi_{k h}\right)}{\sqrt{V_{p c c, u}^{2}+V_{p c c, v}^{2}+V_{p c c, w}^{2}} \cdot \sqrt{I_{s u}^{2}+I_{s v}^{2}+I_{s w}^{2}+I_{s n}^{2}}}
\end{aligned}
$$

In Figure 1, the load impedance of the three single-phase bridge rectifiers are instantaneously changed at $\mathrm{t}=0.5-1.0 \mathrm{~s}$. As a result, the amplitude of load currents at this period increases and it decreases to the same value after $t=1.0 \mathrm{~s}$. From Figure 10, the compensating currents on $d q 0$-frame from APF can track the reference currents calculated by the DQF methods even though the loads are varied. It means that the PI controllers of three current loops with the control strategy proposed in the paper provide a good performance.

In Figure 11, the source currents before compensation $\left(i_{s u}, i_{s v}, i_{s w}\right)$ are highly distorted waveform and the neutral current $\left(i_{s n}\right)$ appears in the neutral line. From Table 2, the $\% T H D_{i, a v}$ of the source currents before compensation at $\mathrm{t}=0.5 \mathrm{~s}$ and $1.0 \mathrm{~s}$ is equal to $25.09 \%$ and $20.94 \%$, respectively. The \%CUF as shown in Table 2 is $14.81 \%$ and $14.24 \%$. These values are extremely greater than the IEEE Standard. After compensation, the $i_{s u}, i_{s v}$, and $i_{s w}$ are nearly sinusoidal waveform and the $\% T H D_{i, a v}$ of these currents is equal to $5.74 \%$ and $3.69 \%$ at $\mathrm{t}=0.5 \mathrm{~s}$ and $1.0 \mathrm{~s}$. Moreover, the $i_{s n}$ is equal to 0 . It means that the unbalanced condition can become a balanced condition after all harmonics eliminated completely. The \%CUF of source currents after compensation is equal to $0.88 \%$ and $1.16 \%$ at $\mathrm{t}=0.5 \mathrm{~s}$ and $1.0 \mathrm{~s}$. These values can follow on IEEE Std.1459-2010. In addition, the results of the power factor correction are shown in Table 2. Before compensation, the $P F$ at $\mathrm{t}=0.5 \mathrm{~s}$ and $1.0 \mathrm{~s}$ are equal to 0.81 and 0.78 , respectively. Therefore, the $P F$ of the system should be improved. After compensation, the $P F$ is nearly unity. From the results, it confirms that the DQF method operated with the APF can provide the unity power factor after compensation. The overall results confirm that the APF can still compensate the harmonic current even though the load is varied.

Table 2. The Performance of the Source Currents before and after Compensations

\begin{tabular}{|c|c|c|c|c|}
\hline \multirow{2}{*}{ Case } & \multicolumn{3}{c|}{ Source current } \\
\cline { 3 - 5 } \multicolumn{2}{|c|}{} & $\% T H D_{i, a v}$ & $\% C U F$ & $P F$ \\
\hline \multirow{2}{*}{$\begin{array}{c}\text { Before } \\
\text { compensation }\end{array}$} & $\mathrm{t}=0.5 \mathrm{~s}$ & $25.09 \%$ & $14.81 \%$ & 0.81 \\
\cline { 2 - 5 } & $\mathrm{t}=1.0 \mathrm{~s}$ & $20.94 \%$ & $14.24 \%$ & 0.78 \\
\hline $\begin{array}{c}\text { After } \\
\text { compensation }\end{array}$ & $\mathrm{t}=0.5 \mathrm{~s}$ & $5.74 \%$ & $0.88 \%$ & 0.99 \\
\cline { 2 - 5 } & $\mathrm{t}=1.0 \mathrm{~s}$ & $3.69 \%$ & $1.16 \%$ & 0.99 \\
\hline
\end{tabular}



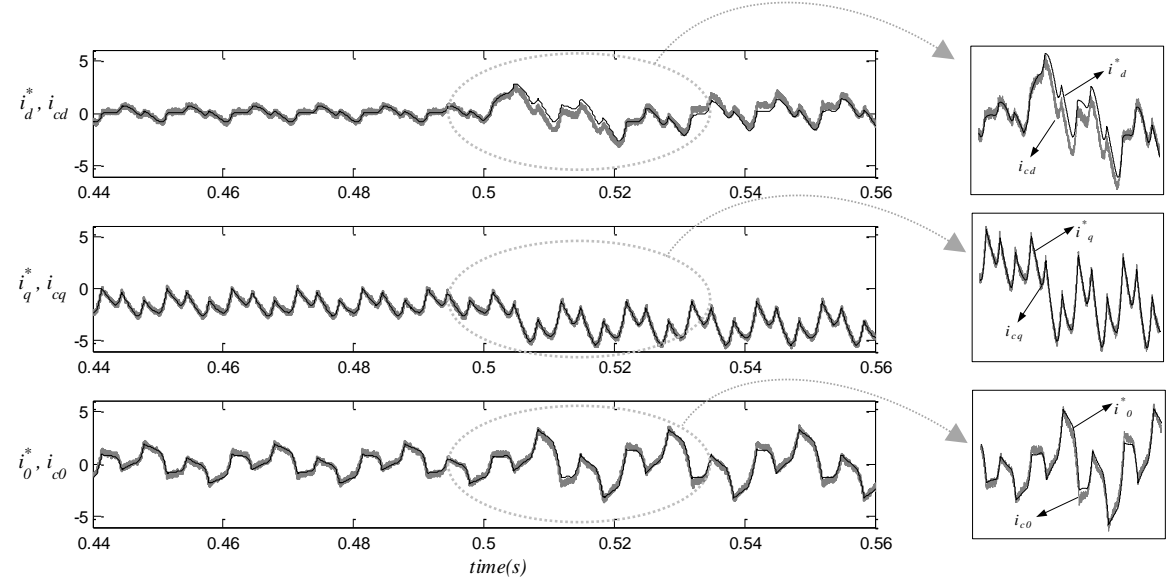

(a) The simulation results for dynamic load changing at $t=0.44-0.56 \mathrm{~s}$
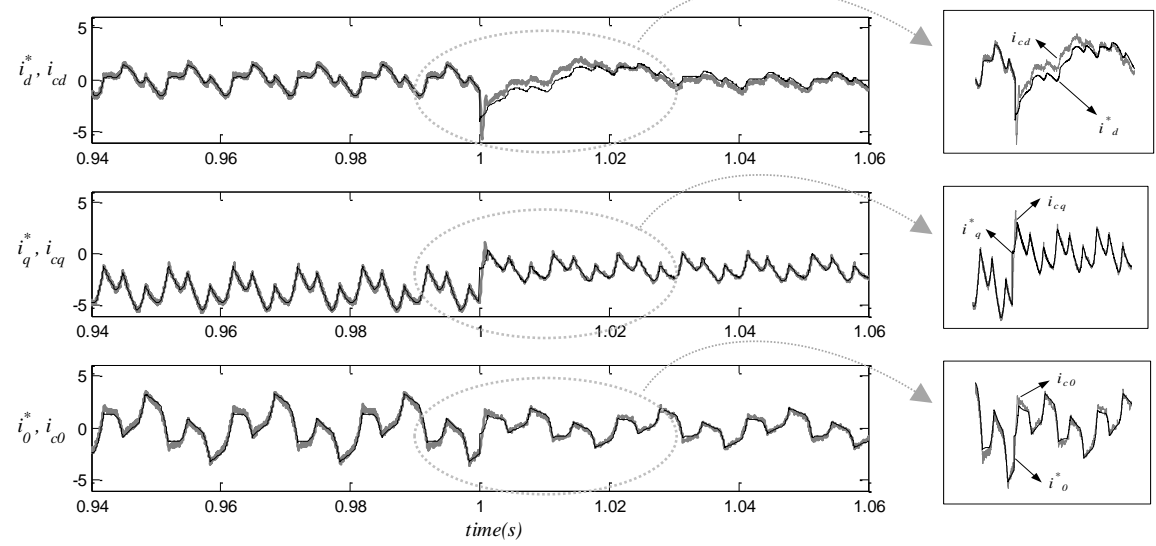

(b) The simulation results for dynamic load changing at $t=0.94-1.06 \mathrm{~s}$
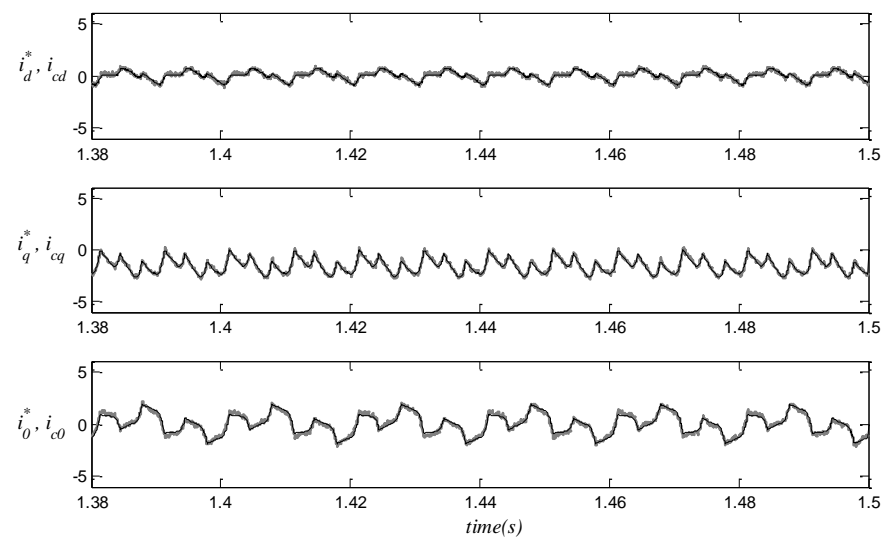

(c) The simulation results for static load at t $=1.38-1.50 \mathrm{~s}$

Figure 10. The Tracking Performance of the Compensating Currents on dq0Frame 

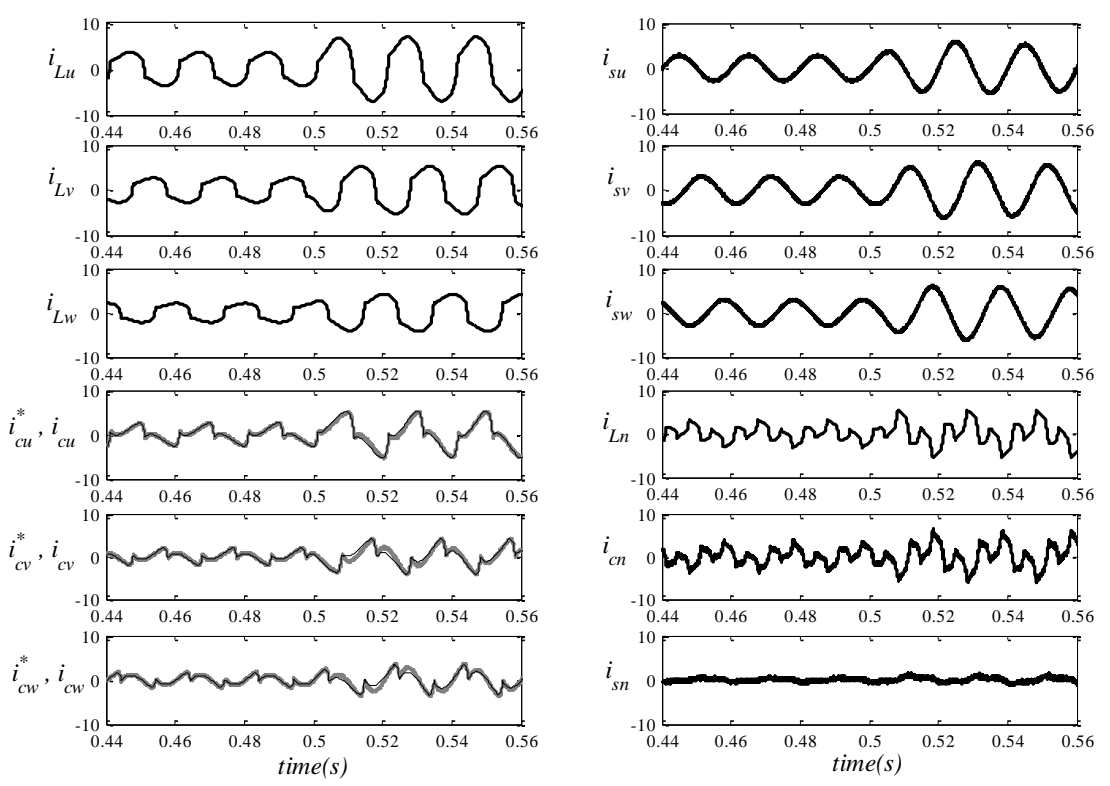

(a) The simulation results for dynamic load changing at $t=0.44-0.56 \mathrm{~s}$
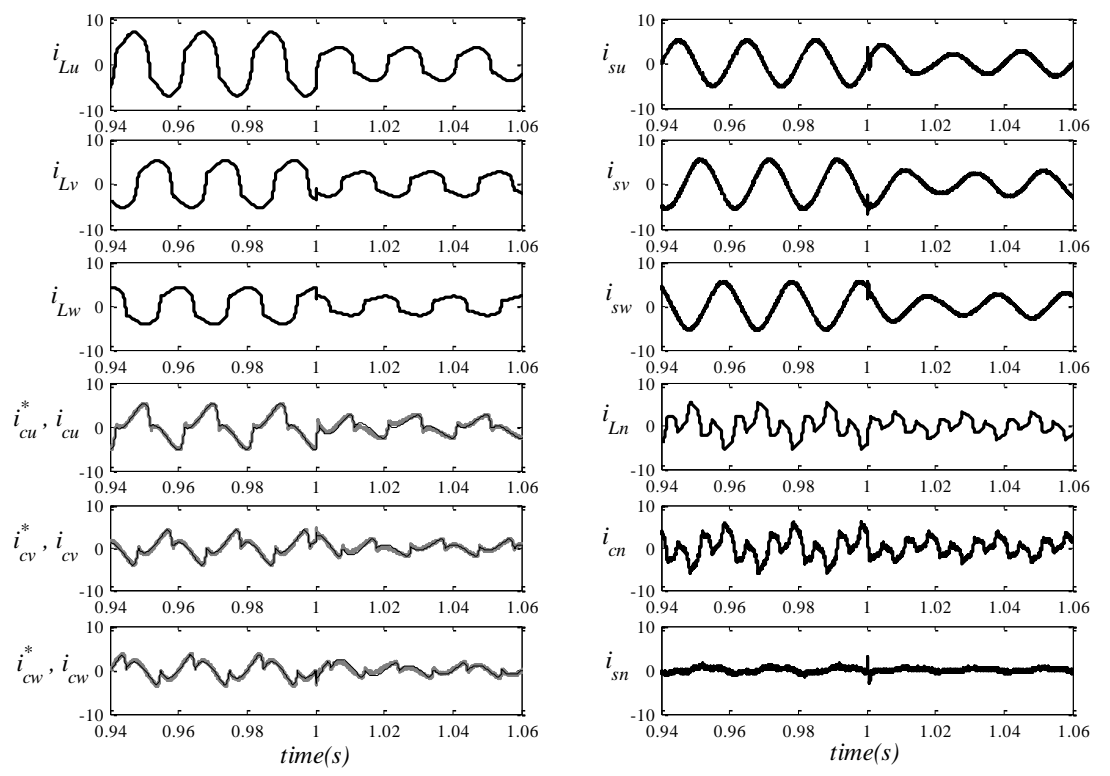

(b) The simulation results for dynamic load changing at t $=0.94-1.06 \mathrm{~s}$ 

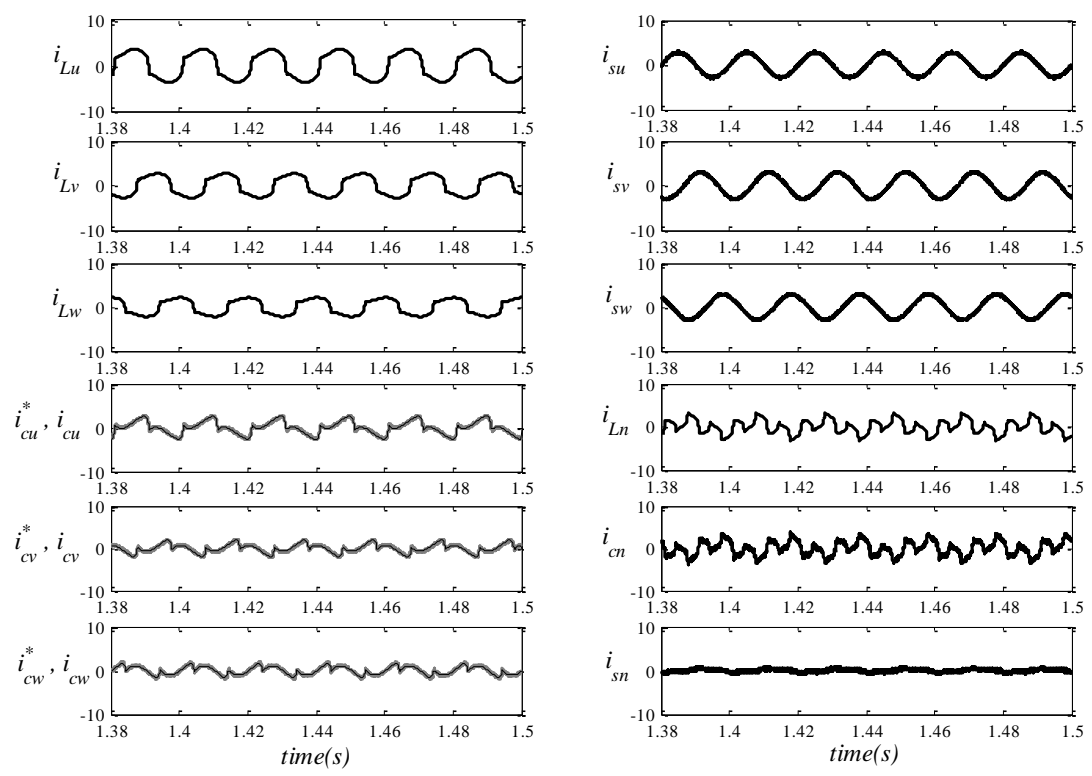

(c) The simulation results for static load at $\mathrm{t}=1.38-1.50 \mathrm{~s}$

\section{Figure 11.The Simulation Results of Harmonic Elimination on Three-phase Four-wire System}

For DC bus voltage responses in Figure 12, the total DC bus voltage $\left(\Sigma V_{d c}\right)$ can track the total DC bus reference $\left(v_{r e f}^{*}\right)$ voltage even though the loads are varied and it is constant at $500 \mathrm{~V}$ in the considered period $(\mathrm{t}=0.44-1.5 \mathrm{~s})$. Moreover, the different DC bus voltage $\left(\Delta V_{d c}\right)$ is approximately to zero. As a result, the PI controllers of the two voltage loops can control the DC bus voltages to the desired values.
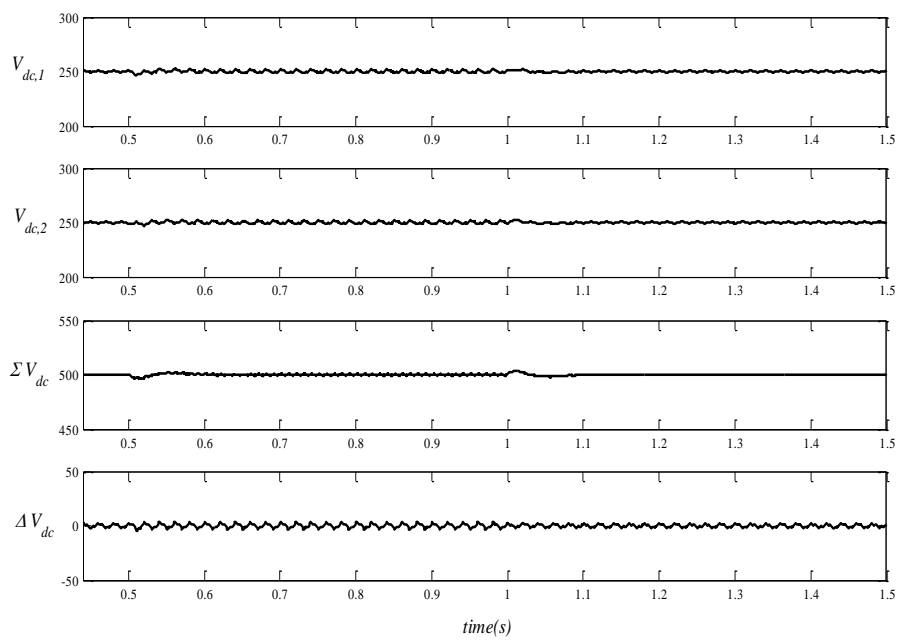

Figure 12. The Simulation Results of the DC bus Voltages for the Three-leg split-Capacitor APF 


\section{Conclusion}

The control strategy of the three-leg split-capacitor APF on $d q 0$-frame in three-phase fourwire system is proposed in the paper. The control strategy operated with the pulse width modulation (PWM) technique is applied to generate the switching signals of the APF. The DQF harmonic detection can be used to identify the all harmonic components in the system. The PI controllers are applied to control the injection of the compensating currents and the DC bus voltages following on the command values. The discrete design approach of these controllers is completely presented in the paper. In addition, hardware in the loop (HIL) is used to test the harmonic mitigation with APF. The results from HIL simulation confirm that the control strategy and the controllers design approach presented in the paper can provide the good performance of the APF. Furthermore, the $\% T H D_{i, a v}$ and $\% C U F$ of the source currents after compensation can follow the IEEE Std.519-1992 and the IEEE Std.1459-2010. Moreover, the APF can also improve the unity power factor of power supply at PCC point.

\section{Acknowledgements}

This work was supported by Suranaree University of Technology (SUT) and by the office of the Higher Education Commission under NRU project of Thailand. The author would like to thank Mr. Tosaporn Narongrit for providing the useful information of hardware in the loop simulation.

\section{References}

[1] P. Indrajit and J. S. Paul, "Effect of Harmonic on Power Measurement", IEEE Petroleum and Chemical Industry Conference, San Diego, CA, (1989) September 11-13.

[2] B. M. Elham, L. W. Clarence and A. G. Adly, "A Harmonic Analysis of the Induction Watthour Meter's Registration Error", IEEE Transaction on Power Delivery, vol. 7,no. 3, (1992).

[3] J. M. Ho and C. C. Liu, "The Effects of Harmonics on Differential Relay for a Transformer", IEEE International Conference and Exhibition on Electricity Distribution (CIRED), Amsterdam, (2001) June 18-21.

[4] IEEE Std. 519-1992, IEEE Recommended practices and requirement for harmonic control in electrical power system, (1993).

[5] L. Gyugyi and E. C. Strycula, "Active ac Power Filters", Proceedings of IEEE Industry Applications Annual Meeting, San Diego, CA, (1989) September 11-13.

[6] F.Z. Peng, H. Akagi, and A. Nabae, "A New Approach to Compensation in Power Systems", Conference Record of the 1988 IEEE Industry Applications Society Annual Meeting, Pittsburgh, PA, USA, (1988) October 2-7.

[7] V. Khadkikar, A. Chandra and B. Singh, "Digital signal processor implementation and performance evaluation of split capacitor", IET Power Electronics, vol. 4, no. 4, (2011).

[8] M. Aredes, J. Hafner and K. Heumann, "Three-Phase Four-Wire Shunt Active Filter Control Strategies", IEEE Transactions on power electronics, vol. 12, no. 2, (1997).

[9] M. Aredes, J. Hafner, and K. Heumann, "A Three-Phase Four-Wire Shunt Active Filter Using Six IGBT's”, EPE'95-European Conference Power Electronics Applications", Pittsburgh, Sevilla, Spain, (1995) September.

[10] H. Akagi, Y. Kanazawa and A. Nabae, "Instantaneous Reactive Power Compensators Comprising Switching Devices without Energy Storage Components", IEEE Transactions on Industry Applications. IA, vol. 20, no. 3, (1984).

[11] M. Takeda, K. Ikeda, A. Teramoto and T. Aritsuka, "Harmonic Current and Reactive Power Compensation with an Active Filter", IEEE Power Electronics Specialists Conference in Proceedings of the 19th Annual, Kyoto, Japan, (1988) April 11-14.

[12] C. L. Chen, C. E. Lin and C. L. Huang, "The Reference Active Source Current for Active Power Filter in an Unbalanced Three-Phase Power System via the Synchronous Detection Method", IEEE Instrumentation and Measurement Technology Conference in Proceedings of the 10th Anniversary, Hamamatsu, Japan, (1994) May 10-12. 
[13] G.W. Chang and S.K. Chen, "An a-b-c reference frame-based control strategy for the three-phase four-wire shunt active power filter", Ninth International Conference on Harmonics and Quality of Power, Orlando, FL, (2000) October 1-4.

[14] S. Sujitjorn, K-L. Areerak and T. Kulworawanichpong, "The DQ Axis With Fourier (DQF) Method for Harmonic Identification", IEEE Transactions on Power Delivery, vol. 22, no. 1, (2007).

[15] K-L. Areerak, "Harmonic Detection Algorithm based on DQ Axis with Fourier Analysis for Hybrid Power Filters", WSEAS Transactions on Power Systems, vol. 3, no. 11, (2008).

[16] M.I.M. Montero, E.R. Cadaval, and F.B. Gonzalez, "Comparison of Control Strategies for Shunt Active Power Filters in Three-Phase Four-Wire Systems", IEEE Transactions on Power Electronics, vol. 22, no. 1, (2007).

[17] L. Limongi, R. Bojoi, G. Griva and A. Tenconi, IEEE Transactions on Industrial Electronics, vol. 3, no. 1, (2009).

[18] G.F. Franklin, J.D. Powell and A. Emami-Naeini, "Feedback control of dynamic systems", PrenticeHall, (2002).

[19]V. Kaura and V. Blasko, "Operation of a phase locked loop system under distorted utility conditions", IEEE Transactions on Industry Applications, vol. 33, no. 1, (1997).

[20] M. A. M. Villalobos and J. F. P. Suarez, "DC Bus Voltage Control in Four-Wire Shunt Active Power Filters with Split Capacitor", 2010 IEEE/PES Transmission and Distribution Conference and Exposition: Latin America (T\&D-LA), Sao Paulo, (2010) November 8-10.

[21] S. K. Jain, P. Agrawal and H. O. Gupta, "Fuzzy Logic Controlled Shunt Active Power Filter for Power Quality Improvement", IEE Proceedings of Electric Power Application, vol.149, no. 5, (2002).

[22] N. Mendalek, "Sliding Mode Control of Three-Phase Four-Wire Shunt Active Power Filter", Canadian Conference on Electrical and Computer Engineering, San Diego, Niagara Falls, (1989) May 4-7.

[23] M. EI-Habrouk, and M. K. Darwish, "Design and implementation of a modified Fourier analysis harmonic current computation technique for power active filter using DSPs", IEE Proceedings Electric Power Applications, vol. 148, no. 1, (2001).

[24] A. E. Emanuel, "Summary of IEEE Standard 1459: definitions for themeasurement of electric power quantities under sinusoidal, nonsinusoidal, balanced, or unbalanced conditions", IEEE Transactions on Industry Applications, vol. 40, no. 3, (2004).

\section{Authors}

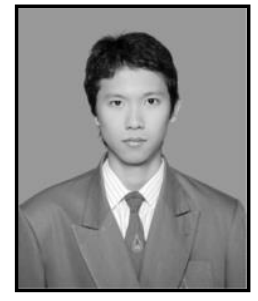

Phonsit Santiprapan was born in Ranong, Thailand, in 1988. He received the B.S. degree and M.Eng. degree in electrical engineering from Suranaree University of Technology (SUT), Nakhon Ratchasima, Thailand, in 2009 and 2011, respectively where he is currently studying toward the Ph.D. degree in electrical engineering. His main research interests include the shunt active power filter, harmonic elimination, artificial intelligence applications, simulation and modeling.

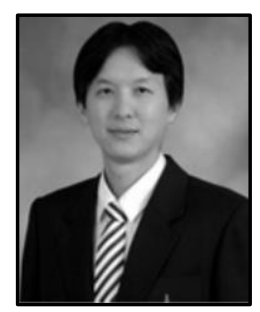

Kongpol Areerak received the B.Eng, M.Eng, and Ph.D. degrees in electrical engineering from Suranaree University of Technology (SUT), Thailand, in 2000, 2003, and 2007, respectively. Since 2007, he has been a lecturer and Head of Power Quality Research Unit (PQRU) in the School of Electrical Engineering, SUT. He received the Assistant Professor in Electrical Engineering in 2009. His main research interests include active power filter, harmonic elimination, artificial intelligence applications, motor drive, and intelligence control systems. 


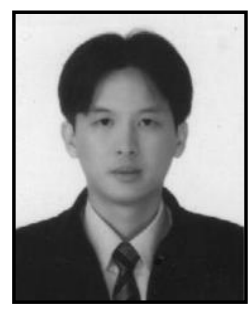

Kongpan Areerak received the B.Eng. and M.Eng degrees from Suranaree University of Technology (SUT), Nakhon Ratchasima, Thailand, in 2000 and 2001, respectively and the Ph.D. degree from the University of Nottingham, Nottingham, UK., in 2009, all in electrical engineering. In 2002, he was a lecturer in the Electrical and Electronic Department, Rangsit University, Thailand. Since 2003, he has been a Lecturer in the School of Electrical Engineering, SUT. His main research interests include system identifications, artificial intelligence applications, stability analysis of power systems with constant power loads, modeling and control of power electronic based systems, and control theory. 